\title{
DECISION-MAKING IN
}

\section{ITALIAN LOCAL POLITICS}

\section{The View of the Communal Councilor}

\author{
SAMUEL H. BARNES \\ Center for Political Studies, ISR \\ University of Michigan
}

In any political system, the quality of political life is largely determined by the relationship between the political actors and the mass of people whose concern with politics is usually sporadic, self-centered, and indirect. Political actors, especially at the national decision-making level, have received a great deal of attention from students of Italian politics. Mass publics have also been extensively studied. Political parties, which are one of the principal means of linkage between elite and mass, have been an important focus of attention for those interested in studying mass mobilization. Here too the major point of interest has been national party elites. And in the study of administration, paramount consideration has likewise been devoted to national problems such as bureaucratic reform, recruitment, and training, and administrative rules and practice.

Of course, this is a general pattern in comparative politics. It is especially fitting in a country such as Italy, in which the central authorities of state and party play a dominant role in the determination of policy for all levels of government. But it is at the local level that the political system touches people most directly. It is here that government is seen by the population in the familiar context of day-to-day administration of

AUTHOR'S NOTE: The interviews for this study were executed by CISER of Rome. Funds were made available by the Ford Foundation Institutional Grant to the University of Michigan for Comparative and International Programs, by a grant from the Horace H. Rackham School of Graduate Studies of the University of Michigan, 
comprehensible problems. It is here that the great issues of ideology and principle are reduced to practical issues of water and sewers, of street lights and school buildings, of an open door at the palazzo comunale or a private cabal controlling the local affairs of state.

In contemporary Italy there is no single entity that is responsible for all local matters. The governmental bureaucracy plays a central role. Parties remain the most important of the informal channels of coordination. Interest groups such as trade unions and religious associations likewise play a significant though informal role.

The communal council is the representative body that unites the concerns of party, formal and informal groups, and the state bureaucracy. Councilors are usually party figures and, at the same time, they have administrative responsibilities. Their activities are circumscribed not only by the accumulated body of administrative law and practice but also directly by agents of the central government. In addition, financial constraints leave little surplus to be used at the discretion of local authorities. Hence their ability to be creative and innovative in the analysis and solution of the problems plaguing the cities of Italy is severely curtailed. As a consequence the role of the communal councilor in the political system has tended to be minimized.

The Italian bureaucracy is crucial in the day-to-day conduct of local affairs. The party dominates in the articulation of local political issues as well as in the mobilization of the population. The communal councilor is often seen as falling between these two stools of administration and party, subservient to both and lacking in authority in his own right.

Is this in fact a true picture? It is the picture reflected, on the one hand, in the literature on administrative law and, on the other, in the conventional wisdom of politicians and scholars alike. The literature on local government and politics in Italy is dominated by the tradition of administrative law, which is concerned with legal norms and not with administrative practices or political behavior. In the words of an American political scientist writing about the study of local politics in his own country, it is a "lost world" from the viewpoint of empirical research (Herson, 1957). ${ }^{1}$ However, there is a vast literature on local communities in Italy that is not legalistic. Much of it is in the anthropological tradition and focuses on single communities. Herein lies its major weakness: it does

and by a Fulbright Visiting Lecturer appointment to the University of Rome granted by the American Commission for Educational Exchanges with Italy. We would also like to express our appreciation to Frank Casale, Franco Portelli, and Peter Joftis for their assistance in various aspects of the research. 
not provide for systematic sampling and is not representative of the total universe of Italian communities.

Another problem in studying Italian local politics is the intrusion of influences from outside the community. It is a general limitation of the community political systems approach that it tends to treat the local system in isolation from its environment, and especially the larger political system. In Italy this temptation is not as strong as it might be, for example, in the United States. The intrusion of the central government in Rome in local administration and the centralized nature of the party system make the lack of local autonomy obvious to all. But this makes it even more difficult to achieve a balanced picture of the local decisionmaking process.

In this exploratory study we will begin to sketch in national patterns in local decision-making in a systematic fashion; we will rely on data from interviews with several hundred communal councilors from all parts of Italy. Our present concern is with the formal decision-making process of the commune; our focus is on the individual councilor and his perceptions of this process. This permits us to evaluate several assumptions concerning local decision-making, including its presumed domination by the mayor, or by interest groups, or by parties; its democratic or nondemocratic nature; its dependence on bureaucrats or on outside experts; and several other often repeated but seldom researched generalizations. Some of these assumptions are shown to be well founded. Others require reformulation. Still others are simply false.

Our data consist of 382 interviews with a national sample of communal councilors taken in the spring of 1968. Although this stands alone as an independent study, it also was conceived as a middle-level-elite data set to complement a national mass sample and a sample of national deputies obtained during the same year. The 75 communes chosen are a one-in-three sample of the 225 used in the mass sample; interviews were actually obtained in only 69 communes. As the mass sample was stratified by size of commune and geographical area, this subsample likewise is roughly representative of communes of different sizes and from different parts of the country. However, while the communes are thus representative of all Italian communes, the councilors were chosen on the basis of a quota of six from each commune to include two Christian Democrats (DC); two Socialists (PSI-PSDI)-the PSI (Socialist Party) and PSDI (Social Democratic Party) were one party at the time of the fieldwork; and two Communists (PCI). Interviewers were instructed to include, where possible, the mayor, vice mayor, and leader of the opposition in order to insure 
representation of the more influential members of the council in the sample. Of the 450 councilmen in the sample, 400 were interviewed; of these, 18 interviews were discarded because they were incomplete or because interviewers selected councilmen who turned out to be from parties other than the major three. The sample obtained reflects a good geographical representation of Italian communes; but because we limited the selection to members of the three major parties and obtained a roughly equal number of councilors from each, it should not be considered a representative sample of Italian councilors.

A further reservation is in order. This is a pilot study using systematic sampling and interviewing techniques in order to generalize about the decision-making process in Italian communes. The need to gather data that were comparable to the deputy and mass interviews, which are not utilized in this analysis, limited somewhat the range of potential theoretical interests that could be pursued. And one of the inherent limitations of the methodology is the focus on cognitive and attitudinal orientations rather than behavior. This is a study of the perceptions of councilmen of the decision-making process. An evaluation of the fit between their perceptions and reality must await studies that profit from different and varied research strategies.

\section{THE STRUCTURE OF LOCAL DECISION-MAKING}

Political decisions may be made anywhere within the political system, but they are formalized in governmental structures. Political roles are likewise acted out within structures. We begin with an examination of these structures and how they are viewed by the individual councilmen.

The formal structure of communal government can be described briefly as follows. Responsibility for local affairs is divided between the provincial prefect and his subordinates, on the one hand, and the elected mayor and council, on the other-a pattern adapted from the Napoleonic system. The communal bureaucracy is responsible to both. The mayor and council are charged with certain responsibilities under national law, and only after these obligations have been met do they have much discretion in dealing with local matters. The mayor, in fact, serves as a representative of the central government as well as of tıe council. The inadequate taxation powers given local government mean that most resources are devoted to meeting legally sanctioned obligations with little left for local initiatives. 
The council is elected from party lists by a system of proportional representation in communes of more than 5,000 inhabitants (at the time of the study-it has since been raised to 10,000); in smaller communes four-fifths of the seats go to the party list that obtains a plurality, with the remainder divided proportionally. It is not uncommon, especially in the smaller communes, for a party list to contain names of local citizens who are not closely identified with that party. However, most successful independents are elected on a party list. The council selects the giunta, which is the cabinet at the local level; it is often a coalition. Members of the giunta, called assessors, have responsibilities for particular subject matters. The council also selects the mayor. In practice, this is decided by the parties in the negotiations leading up to the formation of the giunta. If the parties cannot agree on a giunta, or if the giunta is dissolved by the prefect for alleged irregularities, the commune may be administered directly by the prefect and his representatives. Two of the communes in our sample were under prefectural administration or without a giunta at the time of the study. The common pattern is for the council to reflect the voting strength of the parties in the commune and for the giunta to be a coalition of the leading parties, except in the smallest communes.

Analysis of the composition of the local giunta indicates the great impact that national political arrangements have on local coalitions. The giunta functions as the cabinet at the local level, and its composition determines the climate of opinion within which decisions are made. The pattern of local coalitions before and after the formation of the Center-Left coalition on the national level demonstrates the great impact that the national "Opening to the Left" had on local political matters (see Figure 1). The "Opening to the Left" involved bringing the Socialists into a coalition with the Christian Democrats. It was achieved gradually. First, the PSI supported the government from outside, then took ministerial positions later. The PSDI had been in the government on and off for many years. The cooperation of the two parties led to their merger, so at the time of the study in 1968 they were a single party. They subsequently split again.

The "Opening to the Left" had been pioneered in local politics in several areas of Italy before this arrangement was worked out at the national level. Before the PSI entered the national government, the party was included in very few Center-Left governments ( $7 \%$ of the total) and they were all in communes in northwestern and central (the "Red Belt") Italy. ${ }^{2}$ Almost half of the total communes in the sample had Christian Democratic governments, and another $9 \%$ had Christian Democratic plus 


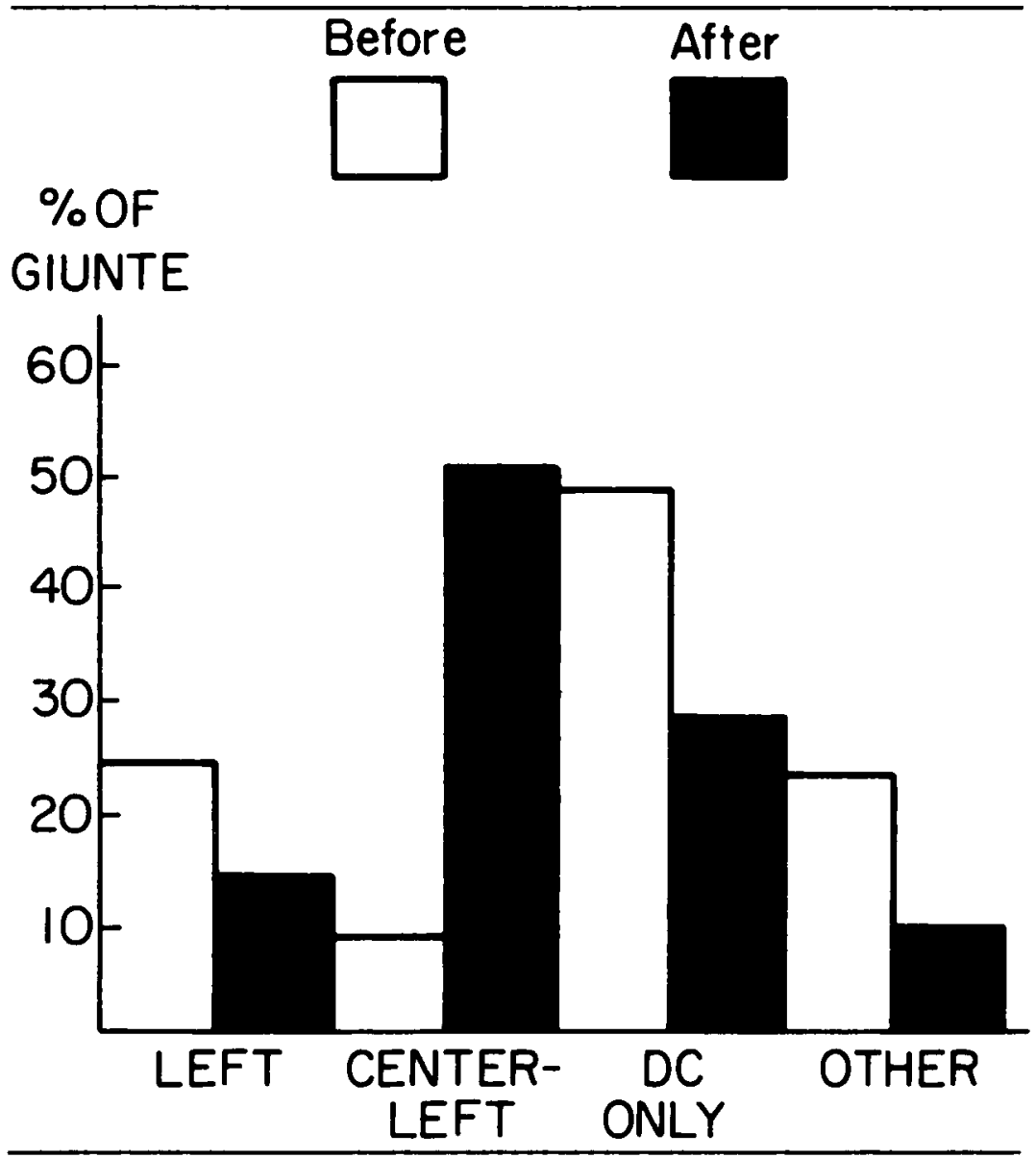

Figure 1: COMPOSITION OF GIUNTE BEFORE AND AFTER FORMATION OF NATIONAL CENTER-LEFT

Social Democratic or Republican coalitions. Almost one-fourth of the communes had Left governments, meaning in most cases Communists or Communists and Socialists. And there were a few Rightist or Center-Left coalitions $(9 \%)$.

In geographical terms, the Left and Center-Left governments were widely scattered, though more common in central Italy than elsewhere. The Center coalitions were likewise widely dispersed, with the Northwest having the heaviest concentration. The DC was stronger in the smaller communes than in the larger. It ruled alone in two out of three communes 
under 20,000. In the smallest communes it was aided by the special electoral system that guaranteed a majority to one party (see Figure 2). In fact, there is a monotonic increase in the participation of the small center parties and a dramatic decline in the monocolori (one party) governments with the increase in communal size.

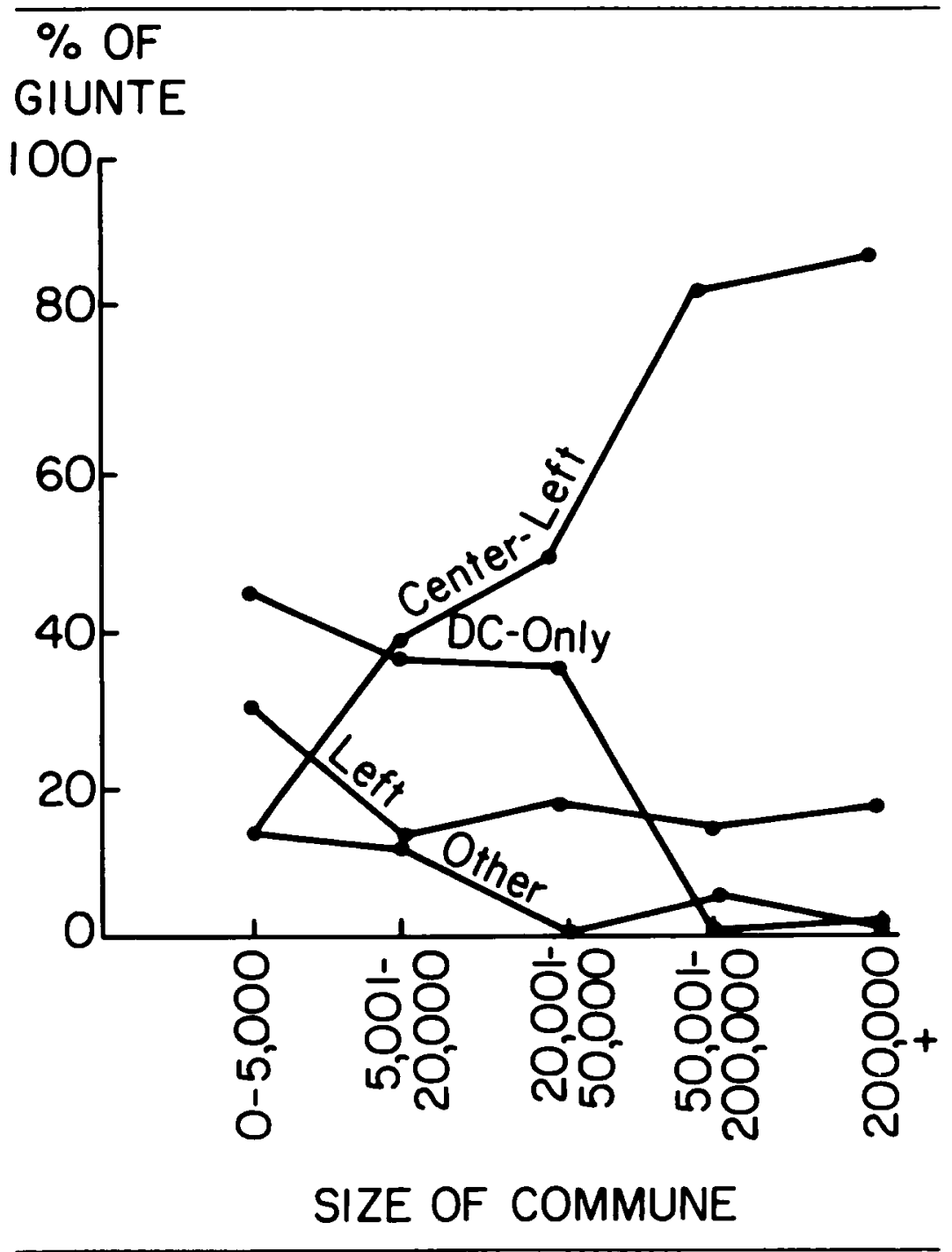

Figure 2: COMPOSITION OF GIUNTE BY SIZE OF COMMUNE 
The maturation of the Center-Left on the national level changed the local patterns considerably. The predominance of the Christian Democratic monocolori or Center coalition local governments was replaced by the predominance of Center-Left coalitions. The change was greatest in the larger communes. Communes with Left governments declined to about $16 \%$ of the sample; the Right and Center-Right percentage likewise declined, while Christian Democratic monocolori governments slipped to $26 \%$ of the total, heavily concentrated in the smaller communes.

In geographical terms the Center-Left is strongest in the Northwest and in the Islands. In the Northeast, Christian Democratic monocolori governments remain strong, as do those of the Left. This results from the polarization that exists in this area of Christian Democrat strength in the Veneto and Leftist strength in Emilia-Romagna, which renders collaboration between the Christian Democrats and Socialists difficult to achieve. Besides this, coalitions are less often necessary because of the strength of each of the blocs.

We asked respondents, "Why and how was the majority changed?"-and found, not surprisingly, that the larger the commune the more often national political motives were cited as the reason, from $9 \%$ in the smallest communes to $22 \%, 32 \%, 40 \%$, and $36 \%$ in the largest communes. In the latter, Christian Democrats were somewhat more likely to view national political considerations as the reason, whereas Socialists in general and especially in the larger communes were likely to view personal motives as responsible. As it was the Socialists who switched sides most often, perhaps they are more sensitive to the many personal motivations that lay behind the party's change in local partners. It is of interest that no one mentioned party intervention as the cause. One expected finding is that polarization of the parties reduces the importance of personal motives. The Northeast and Center, where the Left is especially strong in some areas and the DC in others, were for all parties the areas with the smallest percentage mentioning personal reasons for the change. In these areas the strength of the parties and their affiliated mass organizations undoubtedly leads to a relative depersonalization of politics.

When we examine the councilmen's perceptions of which parties were closest to each other in local politics, the results are inconclusive. As a result of the small sample size it is difficult to evaluate the importance of differences between the Communists' perceptions and those of councilors of the DC and PSI-PSDI. But they indicate that DC and PSI-PSDI councilmen tend to view relations among the Center-Left parties as being much tighter than they are viewed by PCI councilmen. Perhaps this is due 
to the attempt of the Communists to maintain the fiction of ties on the left even when they are in disarray. Perhaps the continued cooperation of Communists and Socialists in trade unions also plays a role in shaping the perceptions of the Communists. At any rate, in several areas Communists view ties with the PSI as being close.

The absence of strong alliances among parties in the smaller communes is likewise striking. More than one-quarter of the councilmen from these communes did not indicate any strong ties, and these were evenly divided among the parties and heavily concentrated in the two smallest categories of communes. This is clear confirmation of the relative absence of party-based partisanship in the smaller communes; it is likely that clientelistic patterns predominate there regardless of the party labels.

\section{SPECIALIZATION IN COMMUNAL POLITICS}

A degree of specialization is common to most assemblies. The demands of government are extensive; the need for attention to details of legislation and administration are considerable. The division of labor is necessary in this field as in others. On the other hand, the work of the communal council, while involving legislation, is not as involved and time-consuming as that of national legislatures; in the smaller communes there may in fact be few decisions to be made. Variation in demands on councilmen is a function of local needs and problems as well as their own political commitments. As mentioned earlier, the autonomy as well as the resources of local governments are limited in Italy. The important role played by the party in Italy suggests the need for models of policy formulation and expertise that incorporate party organization in the decision-making structure.

There are differences in the degree of specialization among the communes according to their size and area of the country. The relationship between specialization and size of commune is not a linear one. Though it is unwise to make too much of the limited number of cases, our evidence shows that the councilors in the DC and PSI-PSDI have the greatest opportunity to take an interest in particular subjects in the middle-sized communes, while in both small and large communes their opportunities seem to be more limited. For the PCI, on the other hand, the maximum is reached in the largest communes (see Table 1). 
TABLE 1

COUNCILMEN WITH SPECIAL FIELDS OF INTEREST BY SIZE OF COMMUNE AND PARTY (in \%)

\begin{tabular}{lccc}
\hline & PCI & PSI-PSDI & DC \\
\hline $0-5,000$ & 37 & 25 & 27 \\
$5,001-20,000$ & 58 & 59 & 54 \\
$20,001-50,000$ & 73 & 82 & 63 \\
$50,001-200,000$ & 50 & 62 & 57 \\
$200,000+$ & 91 & 54 & 42 \\
Party Mean & 61 & 61 & 53 \\
$n=$ & 116 & 123 & 143 \\
\hline
\end{tabular}

It is somewhat surprising that only $58 \%$ of the total claim a special field of interest. Predictably, the Communists and Socialists are more specialized, because they are more tightly organized. But the relatively small difference among the three parties is perhaps more significant than the fact that there are differences.

Geographical differences in specialization also exist (table not shown). There is in general a greater amount of specialization in the Center and North than in the South, and in this as in many other respects, the Islands resemble the Center and North more than the South.

The fields of interest of the councilors do not vary much among the parties: most often cited are public works $(17 \%)$, youth and education $(11 \%)$, and work and welfare $(9 \%)$. Nor are territorial differences important, except that those interested in health are heavily concentrated in the South.

The DC councilors under age forty are somewhat more likely to indicate their special interests than those over forty, which perhaps reflects the growing professionalization of that party. In the other two parties there are no important differences between the two age groupings.

In conclusion, specialization is limited. The relationship between specialization and size of commune is curvilinear, reinforcing our overall finding that in the middle-sized communes the parties and councilmen seem to function most effectively.

\section{SOURCES OF ADVICE ON COMMUNAL MATTERS}

This and the following sections examine the question of how the individual councilman goes about making up his mind on council matters. With the research techniques employed, this process cannot be examined 
directly. Rather, we begin by looking at the councilman's sources of advice on matters before the council on the assumption that these are relevant in conditioning his final decisions. This procedure reveals the perceptions of the councilman as to whom he should consult, but it does not indicate the extent or nature of influence or even of actual interaction. In the following section we examine the councilman's evaluation of the importance of the opinions of various groups.

The respondent was asked, "Before coming to a decision on a communal problem, do you ask information or advice about the problem?" If the response was "yes," the question "From whom?" was posed. The categories used in the code emerged from the respondents' statements themselves.

The first important finding is the absence of large and profound differences among the political parties in the patterns of responses. Although the percentages in each category vary from party to party, the same categories are, in a rough fashion, the principal ones for each. Thus we will give considerable attention to what in fact are sometimes marginal differences among the parties (see Table 2).

Only $11-13 \%$ in each of the parties failed to mention a source of advice, a remarkably similar portion. These respondents are heavily concentrated in the smaller communes, with the pattern being the same for all the parties. Moreover, there are no important geographical differences in these patterns. Councilmen in all parties are more likely to seek advice if their party is represented in the giunta, thus reflecting the fact that they have a greater incentive for consultation when they are in a position to influence

TABLE 2

SOURCES OF ADVICE (in \%)

\begin{tabular}{lrrr}
\hline Source & PCI & PSI-PSDI & \multicolumn{1}{c}{ DC } \\
\hline Own Party & 19 & 30 & 13 \\
Communal Bureau & 3 & 3 & 1 \\
Giunta & 13 & 20 & 24 \\
Associations & 13 & 3 & 5 \\
Other Experts & 28 & 30 & 36 \\
Public Opinion & 9 & 1 & 3 \\
None & 13 & 11 & 12 \\
Other & 2 & 2 & 6 \\
$\quad$ Total \% & 100 & 100 & 100 \\
$n=$ & 116 & 123 & 143 \\
\hline
\end{tabular}


communal decision-making. Councilmen of majority parties are also more constrained to seek contacts outside their own party, perhaps due to their responsibility for the affairs of the entire commune rather than a mere segment of it.

A number of potential sources of advice turn out to have little importance. For example, no one in the sample mentioned the prefect and only three percent mentioned the communal bureau, which is remarkable considering the role of national legislation in local administration. Nor is public opinion an important source of guidance for the councilmen, as only five percent mentioned it and two-thirds of these were Communists. Neither did many respondents mention the multitudinous associations, such as trade unions, farm organizations, religious groups, and so on, that are thought to be of great importance in local politics. Perhaps they will be of increasing importance in the future, as the DC and PCI councilmen under forty referred to them more often than those over forty.

The most important category turned out to be "experts," which here refers to individuals who have specialized knowledge about the subject. However, this category does not include representatives of the party or of interest groups, as these were coded separately. For the three parties combined, $32 \%$ of the total mentioned experts. This reflects a considerable concern with information-gathering. Experts were more often mentioned in Northeastern and Central Italy than in the South and Islands. And it is the councilmen in the larger communes who rely most heavily on this source of advice: except for the smallest category of communes the progression is monotonic, falling from $31 \%$ in the smallest category, to $22 \%$ in the next, then rising to $35 \%, 41 \%$, and, finally, to $59 \%$ in the largest category. Moreover, young councilmen in all the parties mention experts more often. Hence reliance on experts may reflect the greater professionalization and specialization in politics in the larger communes and among the young in general, or it may reflect the complexities of decisions in larger communes and the inexperience of the young. For the DC the progression from the smallest to the largest communes is 20,25 , 39, 53, and 50\%; for the PCI 27, 24, 19, 27, and 64\%; for the PSI-PSDI it is $42,17,21,42$, and $64 \%$. Perhaps for the PCI and PSI-PSDI in the smaller communes these "experts" are in fact party-related advisers from outside the local party who work with the unsophisticated councilmen. In the early postwar years, for example, the Communists and Socialists formed a "League of Communes," a party-related but separate organization, to provide professional and administrative advice to Leftist local governments. 
Two additional sources of advice are of about equal overall importance, but not for the same parties. Some $20 \%$ of the total rely on their own parties as their major sources of advice. PSI-PSDI councilmen most frequently mention their own party $(30 \%)$, with Communists next (19\%) and those from the DC last (13\%). The greater importance attributed to the party by PSI-PSDI councilmen is strange, for it runs counter to impressionistic evidence concerning the strength of the various party organizations. The party is considered more important in middle-sized communes, and hence reflects the general finding that it is there that the party functions most effectively as an organization.

The final source of advice to be considered is the giunta itself. Of the total sample, $19 \%$ mention it; it is listed most frequently by the Christian Democrats (24\%), followed by the PSI-PSDI (20\%) and PCI (13\%). As councilmen with majority ties to the giunta are much more likely to rely on it, this DC reliance is not surprising, as it is a part of the giunta much more often than the other two. Of course, when the party controls the giunta, party and communal leadership tend to merge.

The above findings, it will be recalled, are based on responses to open-ended questions. When the question is placed in the context of weighing the importance to be attached to points of view held by various persons, different orderings emerge. These differences undoubtedly reflect the respondent's normative evaluations of what he thinks is proper. And in this case, the opinions of experts or prestigious people are placed at the bottom of the list. Respondents were asked, "In taking a position on a particular problem what is the order of importance that you give the following opinions?" They were to rank order the following: personal conviction, voters' opinions, party's position, and opinions of experts or prestigious people.

Personal conviction was ranked first by members of every political party. The next most numerous answer was voter's opinions, placed first by roughly equal portions of each party. The party's position followed in importance, with opinions of experts or prestigious people ranked first by the smallest portion of people (see Table 3).

Geographical differences follow no consistent pattern, but size of commune is very important. In the largest communes, councilmen of all the parties were more likely to rank personal conviction first, amounting to $58 \%$ of the DC, $36 \%$ of the PCI, and $55 \%$ of the PSI-PSDI in the communes over 200,000 in size. On the whole, voters' opinions were more likely to be ranked first in the middle-sized communes; this is consistent 
TABLE 3

IMPORTANCE OF VARIOUS OPINIONS BY PARTY

(\% attaching "much" importance)

\begin{tabular}{lrrr}
\hline & PCI & PSI-PSDI & DC \\
\hline Personal Conviction & 31 & 27 & 34 \\
Voter's Opinions & 28 & 24 & 24 \\
Party's Position & 20 & 26 & 14 \\
Opinions of Experts or Prestigious People & 9 & 11 & 16 \\
$n=$ & 116 & 123 & 143 \\
\hline
\end{tabular}

with the other evidence presented that the ties between citizen and local elites are stronger in the middle-sized communes. It is in these communes that party organization and competition are likely to be sufficiently strong to encourage extensive mobilization. In the larger communes mobilization is more impersonal and ties less direct and immediate. There is little mobilization in the smaller communes.

\section{IMPORTANCE OF OPINIONS OF VARIOUS GROUPS}

The previous section examined patterns of consultation. This section will examine the importance attached to the opinions of various groups by the councilmen. As in earlier analyses, it is important to bear in mind that the answers to these questions do not necessarily reflect the actual decision-making rules employed. Councilmen may in fact act on criteria and sources of information quite different from those indicated here. These answers do, however, undoubtedly reflect their normative evaluations of what is the proper answer to give, and in this respect are important. Moreover, it is highly likely that actual decision-making rules are closely related to these evaluations on most issues. From the long-range perspective of a political career it is probable that the value at tached to the opinions of different individuals and groups is going to have a major impact on the content of the decisions made by the councilman. Thus the following analysis should be interpreted as reflecting not the impact of particular groups on particular decisions but rather the influence that they have on the total decision-making process of the councilman.

In the interview, the respondent was asked, "Would you please tell me what importance you would give to the opinions of the following persons, 
that is, do you attach much, some, little or no importance to the opinions of [close friends, members of your family, clerics and religious officials, labor leaders, colleagues or work comrades, managers or employers, politicians, and public opinion in general]." Table 4 summarizes the results by party of each of these. The differences among the parties revealed here are too striking to be artifacts of sampling. They reveal that the DC local leaders claim to pay relatively little attention to the opinions of the working class, whether expressed in references to labor leaders or to work colleagues. And only half as many PSI-PSDI councilmen as PCI respondents attached "much" importance to this group. Furthermore, DC local politicians claimed to pay even less attention to the views of managers and employers than those in the other two parties, regardless of what the actual ties are between business and the DC. ${ }^{3}$ Friends and family are somewhat more important for the DC than for the other two parties. Politicians and public opinion in general are less significant for the DC. As would have been expected, the importance for the PCI of labor leaders and colleagues or work comrades was great.

Given the small numbers involved it is not wise to overstate the importance of territorial differences. However, a few patterns emerge with such strength and consistency that they merit mention despite the statistical hazards involved. Friends and family are important for the Christian Democrats and the Communists in the Northeast, while in the Center, on the contrary, these categories reach their lowest level of importance. For the PSI-PSDI, on the other hand, there are few territorial differences on these two variables. The importance of the opinions of clerics and religious officials is directly related to the importance of

TABLE 4

IMPORTANCE OF OPINIONS OF VARIOUS INDIVIDUALS AND GROUPS BY PARTY (\% attaching "much" importance)

\begin{tabular}{lrrr}
\hline & PCI & PSI-PSDI & DC \\
\hline Close Friends & 55 & 51 & 60 \\
Members of Your Family & 49 & 59 & 61 \\
Clerics and Religious & 11 & 7 & 39 \\
Labor Leaders & 68 & 32 & 15 \\
Colleagues or Work Comrades & 60 & 33 & 21 \\
Managers or Employers & 13 & 11 & 10 \\
Politicians & 55 & 44 & 31 \\
Public Opinion in General & 67 & 65 & 54 \\
$n=$ & 116 & 123 & 143 \\
\hline
\end{tabular}


religion in politics in the area, and this is true for all the parties. For the DC, religious authorities are more important in the Northeast and in the South and less important in the Northwest and Center. The range for the DC is from a low of $23 \%$ of the respondents in the Northwest assigning "much" importance to them, to a high of $50 \%$ in the Northeast. The strange phenomenon of supporters of the two leftist parties paying attention to the opinions of representatives of the church can be explained in the same fashion-where the church is strong, everyone listens. Thus, in the Northeast $19 \%$ and in the South $20 \%$ of the PCI councilmen rate clerical opinions of "much" importance.

Strong patterns likewise emerge in relation to the importance of opinions of union leaders and workers. Where they are electorally important for a party, they are listened to. For the PCI they are very important in the Northeast and Northwest; they are less important there for the PSI-PSDI. In the Center, on the other hand, they are less important for all the parties. Perhaps the strength of the Left in that area renders working-class support unlikely for the DC, while the availability of other sources of support, especially from the agricultural sector, reduces its importance for the PCI. Sources are roughly similar for the PCI and PSI-PSDI in the Center, meaning that unions and workers are less important there than elsewhere for the PCI but more so for the PSI-PSDI; undoubtedly the latter is due to the patterns of cooperation between Communists and Socialists that have developed in this part of Italy.

Opinions of managers and employers are nowhere viewed as important. Perhaps that would be impolitic. There are likewise no dramatic territorial differences in the importance attached to the opinions of politicians. However, there are slight but consistent and monotonic differences for all the parties regarding the importance of public opinion; as one proceeds southward public opinion is stated to be more and more relevant. Though the differences are small, they seem meaningful.

The size of the commune makes a difference in patterns of influence. In particular, the importance of friends and family, especially in the DC, varies according to size. Only in the $\mathrm{DC}$ is there a slight tendency for friends to be more important in the smallest and largest communes. Family seems much more important for all parties in the smallest communes, and for the two secular parties the differences are considerable. Thus $88 \%$ of the PCI members in the smallest communes rate the opinions of family high, with those in the largest communes giving the second highest rating (55\%). 
TABLE 5

IMPORTANCE ATTACHED TO OPINIONS OF LABOR

LEADERS BY PARTY AND SIZE OF COMMUNE

(\% attaching "much" importance)

\begin{tabular}{lccc}
\hline & PCI & PSI-PSDI & \multicolumn{1}{c}{ DC } \\
\hline $0-5,000$ & 63 & 8 & 7 \\
$5,001-20,000$ & 64 & 20 & 10 \\
$20,001-50,000$ & 65 & 32 & 16 \\
$50,001-200,000$ & 81 & 62 & 27 \\
$200,001+$ & 64 & 36 & 17 \\
$n=$ & 116 & 123 & 143 \\
\hline
\end{tabular}

The opinions of clerics and religious authorities were rated highest by DC councilmen in the smallest (53\%) and the largest (58\%) communes. Consistent patterns do not emerge for the other two parties.

The importance of labor unions increased with the size of commune up to the very largest category, where it declines. This is true of all the parties, even though the percentages involved vary widely (see Table 5). For the secular part'es the impact of the opinions of colleagues and work associates follows tine same pattern as that of labor unions. For the DC, however, there is no discernible pattern.

The final three categories of influence suggest no important generalizations. Neither the opinions of managers and employers nor of politicians follow regular patterns that can be detected within a sample of this size. This is also true of public opinion, though there seems to be an irregular pattern of increasing importance of public opinion with increasing size of commune.

This analysis of the importance of the opinions of various groups thus leads to few surprises. In general, the pattern of group relations is the anticipated one.

\section{THE INFLUENTIALS IN DECISION-MAKING}

Having examined group influences on councilmen, we will now consider several other dimensions of influence. The first is the councilman's evaluation of the influence of various political figures in the decisionmaking process. This question was posed in the following manner: "In your judgment, in the decisions of the commune do the following people 
have much, average or no influence?"-and the following figures were named one at a time: mayor, communal assessors, councilmen, local party leaders, provincial party leaders, national party leaders, communal functionaries, provincial functionaries, and national functionaries.

In order to give an overall view of the results, Table 6 summarizes the importance attached to the influence of each source, by party. The results are as expected. The mayor is the most important in all of the parties, with assessors and local party leaders ranked next. The differences among the parties are likewise predictable. PCI councilmen, perhaps because they are more often in the minority, attach more importance to the party leaders at all levels than do those of the other two parties. They also attribute more significance than do others to functionaries at all levels. Indeed, PCI councilmen generally attribute influence much more widely than the others, perhaps reflecting a more politicized view of the local universe. Whether the party is in a majority or minority position in the commune makes a difference for the Communists as it does for the other parties; for $79 \%$ of them from Leftist communes viewed the mayor as having "much" influence. The young more than the old in all parties view the mayor as being more important. Functionaries are also more important for the young.

Territorial differences are not great, but they are consistent. The mayor is most influential within all the parties in the Northwest and Northeast, and least so in the Center. The South and Islands fall in between. Perhaps the dominance of the Left combined with the greater role of the party organization within the Left renders the particular office holders less

TABLE 6

INFLUENCE OF VARIOUS SOURCES ON COMMUNAL POLITICS (\% attributing "much" influence)

\begin{tabular}{lccc}
\hline & PCI & PSI-PSDI & DC \\
\hline Mayor & 57 & 68 & 66 \\
Assessors & 26 & 37 & 28 \\
Councilmen & 16 & 16 & 13 \\
Local Party Leaders & 37 & 22 & 27 \\
Provincial Party Leaders & 28 & 11 & 18 \\
National Party Leaders & 17 & 6 & 10 \\
Communal Functionaries & 18 & 15 & 13 \\
Provincial Functionaries & 22 & 8 & 7 \\
National Functionaries & 18 & 5 & 8 \\
$\quad$ n= & 116 & 123 & 143 \\
\hline
\end{tabular}


important in the Center than they are in other parts of the country. Compared with other areas, the influence of the mayor in the Center is rated lower by the DC and PSI-PSDI councilors than by those from the PCI.

Of greater significance than territory in accounting for differences in influence is size of commune. For the DC and the PSI-PSDI the mayor is most important in the smallest and largest communes; the PCI pattern is irregular. Party leaders in the DC and PCI are more important in the largest communes; for the PSI-PSDI party leaders are more important in the middle categories. Not surprisingly, communal functionaries are more important in the smallest communes for all parties.

The influence of several other groups on local politics was also evaluated, as well as the manner in which that influence was exercised. The question was, "Now I would like to ask your judgment about the intervention of some groups and about the organization of communal politics. To each of the following judgments would you please answer yes or no?" The respondent was then asked whether the group was interested in local politics, whether it was influential, and whether it exercised that influence directly or through a political party. The groups mentioned were communal employees, industry, the clergy, labor unions, agricultural organizations, and the press.

Differences among the parties are those that could be anticipated by knowledge of the party's general orientation (table not shown). Equally of note is the agreement among the parties on some of the issues. There is a large measure of accord that communal employees have little overall interest. The parties view the role of industry somewhat differently. One-third of the PCI group attributed influence to it, which is slightly more than in the other two parties. There are few territorial differences concerning the influence of industry. DC and PCI councilmen from the Center and PCI and PSI-PSDI respondents from the Northwest see industry as most interested.

The impact of size of commune replicates the general pattern that groups are viewed as more involved in the middle-sized communes. And contrary to the conventional wisdom, the clergy are not viewed by any of the parties as more interested in the smaller communes.

Differences concerning the impact of labor unions follow expected lines, with the PCI viewing them as more interested but with less influence. All parties perceive them as being more interested in the Center. And they are hardly involved at all in the smallest communes. The same patterns 
hold for the intervention of agricultural organizations, though the differences are small. They are perceived as interested in the South and by the DC and PSI-PSDI councilmen.

The parties are remarkably similar as far as the press is concerned. It is not of tremendous importance anywhere, though it is seen as even less relevant in the smallest communes.

Thus size of commune seems to be the most important variable affecting the interest and influence of various groups. The payoff for intervention is minimal in the smallest communes; and, for all parties on all issues, intervention and influence tend to rise with size of commune. One partial exception concerns agricultural groups, which, as would be expected, are more active in middle-sized communes than in the smallest and largest ones. A second partial exception concerns the clergy: while the percentage of respondents that views the clergy as interested rises with the size of the commune, the percentage that feels that the clergy has no influence even though interested also rises with size of the commune. Thus the involvement but not the influence of the clergy is seen as rising with communal size. The perceived influence of trade unions grows with the size of the communes, but falls off in the largest. Thus groups seem to have the greatest influence in the middle-sized communes.

A final important point remains concerning influences on local decision-making. The predominance of political and structural over personal variables is remarkable. The respondents' age, occupation, and level of education are not very powerful explanatory variables. They may contribute to understanding particular situations, as there are some differences in their importance among regions and categories of size of commune. But they do not add up to national patterns of differences. Undoubtedly many local situations contradict one another; that is, the better educated may be more anti-clerical in one area and less so in another, and so on.

Only a few generalizations concerning these personal variables seem warranted by our data. Friends and family are somewhat more important for those low in occupational status and education. Within the DC, those lower in educational level have a higher regard for the clergy, but this is not true in other parties. All of these relationships are weak. These individual variables are undoubtedly important in understanding differences between the parties; they do not, however, have much impact on differences within the parties. The importance of structural variables is reaffirmed by the final section, which deals with patterns of decision- 
making in local affairs. First, however, sources of initiative within the council will be examined.

\section{INITIATIVE WITHIN THE COUNCIL}

There is overwhelming agreement that the giunta takes the initiative in proposing new measures in the commune. However, party differences are of interest, as $66 \%$ of the PCI, $91 \%$ of the DC, and $89 \%$ of the PSI-PSDI respondents credit the giunta with the function of initiating proposals. These differences undoubtedly reflect the fact that the Center-Left parties can rely on the giunta for leadership while the PCI, being usually in opposition, must look elsewhere. Thus when the giunta is Leftist, $90 \%$ of the PCI councilmen credit it with most local initiative, compared with $56 \%$ when it is Center-Left. The PSI-PSDI, which participates in most Left and Center-Left coalitions, gives the giunta high scores across the board. The DC does also. Obviously, the giunta provides the principal leadership for the governing parties, whichever they are.

Among ordinary councilmen-those who are not mayors, vice mayors, assessors, or opposition leaders-those in the PCI most frequently view themselves as having important roles in local decision-making. Furthermore, the Communists in the sample attributed more importance to national leaders. Only in the PCI are territorial differences important on this variable, as more PCI respondents in the South than elsewhere attach importance to their own views and to those of national party leaders.

Size of commune seems not to make much difference. National party leaders are viewed as more important in the larger communes, as would be expected, and individual councilmen are slightly more often viewed as responsible for local initiatives in the smaller communes. But the differences are not dramatic when viewed against the overwhelming majority everywhere that views the giunta as the most important source of initiative.

\section{HOW THE COUNCIL DECIDES}

The final section is devoted to an analysis of the councilor's perceptions of patterns of local decision-making. The political process within the council was investigated by means of a forced-choice technique that imposed a structure on the almost infinite variation possible in local 
decision-making. The respondent was asked to examine four statements concerning the councils' decision processes and to choose the one that best characterized his own experiences. The alternatives are as follows:

(1) The councilmen group themselves to support or oppose various provisions according to the merit of each problem.

(2) Councilmen of the same party vote together but alliances among parties change according to the various problems.

(3) For the majority of problems, alliances among various parties are more or less permanent.

(4) Councilmen who are followers of local personalities or who belong to the same social class vote together.

The party divisions on this question are presented in Table 7 .

An initial observation is that the overall differences among the parties are minimal. The reason is that structural factors are more important than either party or individual characteristics of councilmen. Although the number of cases is small, some differences emerge in sharp relief. For example, permanent alliances are of less importance in the South; and in this respect councilmen from the Islands are more similar to those from the North than from the South. The shifting nature of local politics in the South is again apparent here, as is the variation between the patterns of the Islands and mainland Southern Italy. Other interesting findings concern differing perceptions of reality: what to the PCI and PSI-PSDI in the Center seem to be permanent alliances are viewed by the Christian Democrats as changing party alliances. Three times as many DC and two times as many PSI-PSDI councilmen view alliances as permanent when in the majority rather than the minority. The broad outlines of differences are clear: permanent party alliances are of greatest importance in the larger

TABLE 7

HOW THE COUNCIL DECIDES, BY PARTY

(\% choosing that al ternative)

\begin{tabular}{cccc}
\hline Alternative & PCI & PSI-PSDI & DC \\
\hline 1 & 28 & 26 & 27 \\
2 & 27 & 24 & 26 \\
3 & 35 & 41 & 41 \\
4 & 10 & 9 & 6 \\
Total \% & 100 & 100 & 100 \\
$n=$ & 116 & 123 & 143 \\
\hline
\end{tabular}


communes. They are of least importance in the communes of the mainland South. And the same situation is often viewed differently by the parties.

Additional evidence of the relatively greater impact of situational and structural effects over partisan affiliation comes from a variance components analysis of the choice of alternative 3 ("For the majority of problems, alliances among various parties are more or less permanent"). ${ }^{4}$ This analysis takes the selection of this third alternative as the dependent variable and could accept up to forty independent variables to explain variations in the dependent variable.

Two different analyses were performed. The first included twelve independent variables or predictors including geographical area, party, majority-minority relationship with giunta, communal majority, source of communal initiatives, relations with prefect, and five variables that referred to personal characteristics of the respondent-conception of democracy, social class, education, frequency of church attendance, and occupation. The analysis program tries each of these predictors and chooses the one that reduces the variance in the dependent variable by the largest amount. It splits that independent variable into two components by using every possible combination of the codes of the variable and selects the bifurcation that explains the largest amount of variance. It then proceeds with each of the two parts and seeks to split them in a similar manner. The result is a "tree" in which the branches continue to fork until no more variance is being explained or the number of cases (as specified by the analyst) is too small.

The results of the analysis using twelve predictors demonstrate clearly that whether the commune has a Center-Left majority or not is the best predictor of the respondent selecting alternative 3 . The second best is geographical area of the country. Only then does educational level enter as a predictor, and it is the only personal characteristic of the councilman to appear. The three predictors of communal majority, area, and education together explain $32 \%$ of the total variance.

Unfortunately, the large number of variables initially chosen multiplies missing data problems; full data existed for only 213 of the 382 respondents. Consequently, the analysis was repeated with only the five best predictors of the above analysis, which were communal majority, geographical area, party, size of commune, and education. Data were available on all five for 354 respondents. Communal majority-Center-Left against other combinations-again emerged as the best predictor, followed by geographical area as in the previous analysis. Party emerges at the third split, along with size of commune. Party is closely related to education 
because of the low levels of formal education of so many Communists. But education itself is the least important of the five predictors.

This analysis suggests several conclusions. One is that there are remarkable similarities of perception among the councilmen in the sample, because the objective datum of communal majority was the best predictor of the dominant style of local decision-making. This is undoubtedly a phenomenon that does vary mainly with the composition of the majority. With geographical area next, the best predictors of this style are thus structural variables rather than the personal idiosyncrasies of the respondent or his party affiliation. The fact that councilmen of different parties reach the same conclusions concerning the patterns of local decisionmaking increases confidence in their other perceptions. And this analysis also reinforces other findings that demonstrate the relatively greater importance of structural factors over personal and political ones in many aspects of local politics.

This conclusion is confirmed by a "tree" analysis of the predictors of the existence of a Center-Left coalition giunta. The two variables, size of commune and geographical area, explain 56\% of the variance in the composition of the giunta. It is clear that outside of Northeastern Italy, the Center-Left formula is dominant in the larger communes; $94 \%$ of the respondents in those with over 50,000 inhabitants serve under Center-Left giunte. And even in the smaller communes (under 50,000), $72 \%$ of the councilmen in the Northwest, North-central, and Island Italy work with Center-Left giunte, compared with only $20 \%$ in similar-sized communes in other areas.

\section{CONCLUSIONS}

Several general findings emerge from this examination of local decision-making. The importance of the environment of local decisionmaking has been firmly established, as well as the impact of national considerations on that environment. The "Opening to the Left" on the national level greatly altered patterns of conflict and cooperation in local politics. The majority and minority have differing patterns of perceptions of how communal decisions are made, varying estimates of the influence of groups, and contradictory opinions of the nature of influence within the council. Although there are many differences among the parties, on many variables party differences are not as important as differences in relationship to the giunta. The mayor is everywhere the dominant figure. 
$\mathrm{He}$ is especially important for the majority parties and in the smallest communes. And, probably because of the party's dominance of the majority and of the smallest communes, he is also important within the Christian Democratic party.

Territorial differences are the generally expected ones. Parties have somewhat different profiles in areas of strength and weakness. Areas of intense competition and polarization, such as the Northeast and Center, have profiles different from other areas. The mainland South exhibits traces of clientelism and easily shifting political alliances to a greater degree than elsewhere. The Islands are more similar to the rest of Italy than to the South.

Communes of different size have quite different patterns. In the smallest communes national considerations are least important. Friends and family are very highly ranked, groups do not take much of an interest in local affairs, and the party is not omnipresent. There is little specialization. The mayor is the dominant figure. Party, groups, professionalization, and specialization assume commanding importance in the middle-sized communes. It is here that there seems to be the closest linkage between the citizen and his representative. The larger communes exhibit a more impersonal politics. National considerations assume greater importance and politicians have an indirect relationship with citizens. Public opinion in general becomes more relevant. The involvement of groups and individuals in local matters increases with size of commune. However, their influence-as opposed to interest-seems to be greater in the middle-sized communes. Perhaps interest group politics focuses more on the bureaucracy in the larger communes, but this is mere speculation.

To conclude, in small communes personal considerations emerge as most important. Politics in the largest communes is the most impersonal and closely reflects national patterns. It is the middle-sized communes that approach the classical pattern of tightly organized parties, wide consultation, and an active group life.

But the most important general finding that emerges from our research is that there is no single national pattern. Large, middle-sized, and small communes are different in their patterns of decision-making. The Center and South are different; the Northwest and Northeast are different. Despite the formal similarities of the institutions of local government, local decision-making reflects the variety of a diversified polity. 


\section{NOTES}

1. For an excellent recent study of some limited aspects of local politics in Italy see Fried (1971). For an introduction to the literature, see Fried $(1971,1963)$.

2. Italy is divided into geographical areas-the Northeast, North-central, Northwest, Center, South, and Islands. As Italian "regions" are specific administrative subdivisions much smaller than these units, we will call the areal subdivisions "areas," or "geographical areas." All percentages refer to the sample. Official data on the composition of local giunte are difficult to find.

3. La Palombara (1964) describes the close ties between business and the DC. Perhaps the responses should not be taken at face value.

4. See Sonquist et al. (1971) for a description of these procedures.

\section{REFERENCES}

FRIED, R. C. (1971) "Communism, urban budgets, and the two Italies: a case study in comparative urban government." J. of Politics 33: 1008-1051.

--- (1963) The Italian Prefects: A Study in Administrative Politics. New Haven, Conn.: Yale Univ. Press.

HERSON, L.J.R. (1957) "The lost world of municipal government." Amer. Pol. Sci. Rev. 51: 330-345.

LA PALOMBARA, J. (1964) Interest Groups in Italian Politics. Princeton: Princeton Univ. Press.

SONQUIST, J. O., E. L. BAKER, and J. N. MORGAN (1971) Searching for Structure. Ann Arbor: Institute for Social Research. 